\title{
International business studies: Are we really so uniquely complex?
}

\author{
Herman Aguinis ${ }^{1}$ and \\ Kelly P. Gabriel ${ }^{1}$ \\ ${ }^{1}$ Department of Management, School of Business, \\ The George Washington University, 2201 G St. \\ NW, Washington, DC 20052, USA
}

Correspondence:

H Aguinis, Department of Management, School of Business, The George Washington University, $2201 \mathrm{G}$ St. NW, Washington, DC 20052, USA e-mail: haguinis@gwu.edu
Received: 22 February 2021

Revised: 17 April 2021

Accepted: 12 July 2021

Online publication date: 6 September 2021

\begin{abstract}
Articles in Journal of International Business Studies (JIBS) and elsewhere have argued that international business (IB) is a uniquely complex field. We offer an alternative perspective and evidence that IB is not so uniquely complex compared to organizational behavior, strategic management studies, and entrepreneurship. We argue that viewing IB as uniquely complex is likely a result of what a vast body of social psychology research has uncovered and labeled false uniqueness bias: the tendency for people to believe that they are unique compared to others. We discuss selective accessibility and focalism as underlying psychological mechanisms of this bias. We acknowledge advantages of claiming uniqueness, but argue that it is now more beneficial and realistic to highlight similarities. Doing so will allow IB to import and export theories and methods and thereby make IB borders even more permeable. In turn, increased permeability is likely to lead to further theoretical progress that will benefit IB research, practice, and its positive impact on organizations and society even further. To illustrate advantages of not exaggerating IB's uniqueness, we use JIBS Decade Award winners as exemplars of studies that are admired and impactful precisely because of their focus on similarities rather than unique complexity.
\end{abstract}

Journal of International Business Studies (2022) 53, 2023-2036.

https://doi.org/ | 0. I057/s4 I 267-02 I-00462-x

Keywords: international business; complexity; research methodology; false uniqueness bias

The online version of this article is available Open Access

\section{INTRODUCTION}

Articles published in Journal of International Business Studies (JIBS) and elsewhere have argued that international business (IB) is a very complex field (e.g., Bello \& Kostova, 2012; Cheng et al., 2014; Peterson, 2004). Consequently, the reasoning is that this high degree of complexity makes IB particularly unique and different from other fields both theoretically and methodologically (Aguinis et al., 2020; Bello \& Kostova, 2012; Cuervo-Cazurra et al., 2013, 2016; Doz, 2011; Norder et al., 2021; Sullivan \& Daniels, 2008). For example, the edited volume Research Methods in International Business, which is based largely on articles published in JIBS, includes the terms "unique" or "uniqueness" 30 times (Eden et al., 
2020). The most recent example arguing for IB's unique complexity is a JIBS article by Eden and Nielsen (2020: 1610), which stated that "complexity is the underlying cause of the unique methodological problems facing international business research."

We offer the alternative view that IB is not so uniquely complex theoretically or methodologically. Our perspective is based on evidence that other fields are similarly complex. To do so, we draw upon Eden and Nielsen's (2020) complexity framework including three dimensions: multiplicity, multiplexity, and dynamism. Specifically, we show that organizational behavior, strategic management studies, and entrepreneurship are similarly complex because, just like in IB, theories need to consider a variety of agents and actors (i.e., multiplicity), a variety of relationships and interdependencies among these agents and actors (i.e., multiplexity), and processes as they unfold over time (i.e., dynamism in environments). We also provide evidence that IB's interdisciplinary nature is similarly not unique compared to these other fields.

In an effort to understand its origin, we use psychological theory to explain a likely reason why IB is often described as being so unique. Specifically, we argue that this conclusion is likely a result of what a vast body of social psychology research has uncovered and labeled false uniqueness bias (e.g., Suls, 2007; Suls \& Wan, 1987). False uniqueness bias is the tendency for people to incorrectly believe that they are different from others. Building upon psychological theory, we describe two underlying mechanisms for why false uniqueness bias has likely emerged among IB researchers: (i) selective accessibility (i.e., information about our own field is much more easily accessible compared to information on other fields), and (ii) focalism (i.e., giving more weight to information that is readily available).

We would like to emphasize that our article is most certainly not intended to be a criticism of the IB field. On the contrary, there are advantages associated with claiming uniqueness - particularly when a scientific field is in its nascent stage. However, IB has now reached maturity and legitimacy (Cantwell \& Brannen, 2016). For example, as an indication of IB's stature in the global academic community, Clarivate's June 2021 Web of Science edition ranked JIBS as the \#6 most impactful journal in the Business category (out of 153 journals), and also as the \#7 most impactful journal in the Management category (out of 226 journals). We believe that by considering not only differences from other disciplines, but also similarities, IB can harness its interdisciplinary nature (Cheng et al., 2009; Dunning, 1989) and more easily import and export theories and methods (Buckley et al., 2017). Clearly, importing and exporting theories requires selectivity (e.g., consistency in concepts, explanatory power; Kenworthy \& Verbeke, 2015). Similarly, importing and exporting methods also requires selectivity (e.g., consistency in units of analysis, data availability; Peterson et al., 2012). Reassuringly, IB has moved from being predominantly a net importer (Sullivan et al., 2011; Yeheskel \& Shenkar, 2009) to net exporter (Cantwell et al., 2014). Accordingly, we believe that an overemphasis on uniqueness is not only detrimental to IB but also to other disciplines that have much to gain from IB's theories and applications (Cantwell \& Brannen, 2011). Overall, as noted eloquently by Cheng et al., (2009: 1072), "Whereas it is the rare disciplinary scholar who reaches outward across boundaries, IB cannot similarly sustain itself as a field of inquiry if we mimic this insularity." Our perspective is that increased permeability is likely to lead to further theoretical progress that will in turn benefit IB research, IB practice, and enhance IB's positive impact on organizations and society even further.

\section{COMPLEXITIES UNIQUE TO INTERNATIONAL BUSINESS STUDIES: THEORIES, PHENOMENA, AND METHODOLOGY}

Many IB researchers refer to the field as being uniquely complex regarding its theoretical foundations (e.g., Cuervo-Cazurra et al., 2016). Specifically, it has been argued that IB is unique because no single theoretical lens or discipline can provide a complete explanation (Cantwell \& Brannen, 2011; Cheng et al., 2009). Bello and Kostova (2012: 541) explained that this "layering" of theories wherein one draws from another is both a "blessing and a curse." While in the past this diversity of theoretical approaches was seen as a threat to IB's standing as a legitimate field, IB has proven over time that it has its own theories, constructs, and bases of knowledge and that multi-theory approaches can be an added benefit.

Many have also argued that IB is uniquely complex regarding the phenomena of interest. Specifically, multiple and cross-border locations of the firm create inherent complexity (Cuervo-Cazurra 
et al., 2016). This issue affects IB as well as international management, which refers to "theory, research, and practice of management with a cross-border or cross-cultural dimension" (About the IM Division, 2021) and therefore is encompassed by IB. This inherent type of complexity can only be understood properly through multiple levels of observation given that firms are embedded in multifaceted contexts with economic, cultural, legal, and political elements (Birkinshaw et al., 2011; Cheng et al., 2009). Accordingly, many scholars have emphasized the need to approach IB phenomena at a variety of levels (Arregle et al., 2006; Eden et al., 2020; Goerzen et al., 2013), with appropriate attention paid to nesting and crosslevel effects (Aguinis et al., 2013; Andersson et al., 2020). Context is also an important part of this phenomenological complexity (Bello \& Kostova, 2012; Cheng et al., 2009; Shenkar, 2004). For example, Teagarden et al. (2018: 303) argued that, "Context differentiates international business from traditional business research." Other scholars have discussed the deeply embedded contextual nature of IB phenomena and determined that these can only be understood by examining the contextual processes (Cheng et al., 2009). Therefore, scholars recommend employing a context-rich approach (Shenkar, 2004) that includes not only environmental analysis but also time-sensitive context.

As another argument regarding unique complexity that is related to the above-mentioned theoretical and phenomenological issues, Eden (2008) argued that boundary-spanning differentiates IB from other disciplines. That is, IB research is cross-border, cross-cultural, and cross-discipline, and the breadth and variety of potential research topics in IB inevitably creates methodological challenges not faced by researchers in other domains. Eden (2008) conceptualized IB as an umbrella covering the international aspects of all business disciplines. Moreover, Eden and Nielsen (2020: 1613) argued that because of this unique nature of IB, "Methodology challenges faced by IB researchers should not be simply conflated with methodological issues facing scholars in mainstream disciplines." Similarly, Cuervo-Cazurra et al. (2016) noted unique methodological challenges that arise with phenomenological complexity. For example, Cuervo-Cazurra et al. (2016: 881) argued that "the complex nature of international business research, with its cross-country and multilevel nature, complicates the empirical identification of relationships among theoretical constructs."
Moreover, in the first chapter of Eden et al.'s (2020) excellent and comprehensive tome on IB research methodology, Eden et al. (2020: 10) noted at the outset that, "These methodological challenges, we argue, seem to plague IB research because of the types of research questions asked and the cross-border contexts studied."

\section{UNIQUE COMPLEXITY: THREE DIMENSIONS}

Based on our previous section, there are many different issues and topics that have been addressed in the ongoing conversations about IB's uniquely complex status. So, in an effective effort to organize and improve clarity of the "IB is uniquely complex" literature, Eden and Nielsen (2020) offered a useful taxonomy of complexities unique to IB. They argued that, "IB research is designed to explore and explain the inherent complexity of international business, which arises from the multiplicity of entities, multiplexity of interactions, and dynamism of the global economic system" (2020: 1609). Accordingly, they aptly used these three dimensions of complexity to explain some of the challenges supposedly not faced by researchers in other domains.

First, multiplicity refers to the number and variety of actors, industries, countries, contexts, cultures, or institutions in the global economic system. For example, Fainshmidt et al. (2018) created a framework to capture the diverse institutional contexts of understudied economies, and their classification of the national institutional context illustrates the variety of institutional systems in the global economy. As another example, mode of entry and location choice are areas where there are vast and varied actors, countries, and contexts (Eden \& Nielsen, 2020).

Second, multiplexity refers to the number and variety of relationships and interdependencies among entities. For example, Gemmetto et al. (2016) analyzed the world trade multiplex (WTM), representing the import-export relationships between countries in different commodities, and found that the WTM exhibits strong multiplexity and multireciprocity. Other examples of multiplexity are multinational enterprises' (MNEs') inter- and intra-organizational networks, buyer-supplier networks, and international strategic alliances (Cuypers et al., 2020).

Third, dynamism refers to the constant change, activity, or progress in environments, relationships, and constructs. For example, Sun et al. (2010) 
examined the relationship between the embeddedness of MNEs in host-country political networks and their competitive positions in host emerging markets. Their longitudinal study uncovered the underlying mechanisms that lead to the declining value of MNE political embeddedness in a politically stable emerging economy. As another example of dynamism, Buckley and Casson (2001) saw uncertainty in long-term planning as a unique challenge for IB. Although Eden and Nielsen (2020: 1614) referred specifically to "dynamism of the international business system [which] generates risk, uncertainty, volatility, and ambiguity," there are many other forms of dynamism frequently discussed in IB such as dynamic capabilities (Teece, 2014), communicative interactions (Szkudlarek et al., 2020), dynamic endogeneity ( $\mathrm{Li}$ et al., 2021), and the role of history (Jones \& Khanna, 2006).

Finally, an issue that seems implicit in the three aforementioned complexity dimensions is the interdisciplinary nature of IB. For example, as noted by an anonymous reviewer, former JIBS Editor-inChief John Cantwell frequently referred to JIBS as a "row journal." The disciplines were the columns, and IB was cross cutting and thus a "row journal." This unique interdisciplinary nature seems to, at least in part, result in IB's unique complexities (Cantwell \& Brannen, 2011).

The complexities we described above are clearly important for IB theory and methodology. However, we conducted a side-by-side comparison with other fields and reached the conclusion that these complexities are actually not particularly unique to IB. Next, we address this issue in detail.

\section{SIMILAR COMPLEXITIES IN ORGANIZATIONAL BEHAVIOR, STRATEGIC MANAGEMENT STUDIES, AND ENTREPRENEURSHIP}

As illustrations, we selected organizational behavior, strategic management studies, and entrepreneurship because they are conceptually and empirically adjacent fields. Akin to IB, their foci also range from the micro to the macro level of analysis (i.e., individual, team, firm, environment), they rely on theories from similarly foundational disciplines (e.g., psychology, economics, sociology), and also on a set of similarly diverse ontological (e.g., new positivism, structuralism) and methodological approaches (e.g., quantitative, qualitative). As the basis for our comparison, we used Eden and Nielsen's (2020) three-category complexity taxonomy. As a preview, Table 1 summarizes results of our comparative analysis.

\section{Organizational Behavior (OB)}

$\mathrm{OB}^{\prime}$ 's goals are to understand, predict, and manage human behavior in organizations (Luthans et al., 2015). Each of the three dimensions of complexity play a critical role in OB's theory and research. Regarding multiplicity, OB research is concerned with a variety of actors, contexts, cultures, and levels of analyses (Klein \& Koslowski, 2000). For example, OB research on organizational demography has turned away from treating gender, social class, income, and occupation as control variables to using these variables to provide theoretically grounded explanations for often unexplained effects involving a multiplicity of actors (Johns, 2018). Regarding multiplexity, OB theories include a large number and variety of interdependencies among people and groups. For example, emotional contagion research has shown that group members become "infected" by others' emotional states and that contagion can be a major mechanism for leaders to transfer emotional states to team members (Ashkanasy \& Dorris, 2017). Regarding dynamism, OB scholars similarly seek to understand how individuals' and groups' attitudes and behavior change and fluctuate over time, as well as how the environment and context can influence this change. For example, research on job performance has evolved to no longer view performance as static, but as dynamic over not just long but also short timeframes (e.g., minutes, hours, days, weeks) and that this variation has implications for human capital acquisition and employee well-being (Aguinis, 2019; Dalal et al., 2020).

Although the above illustrations show the centrality of multiplicity, multiplexity, and dynamism across various OB theories, it is useful to show how all three of these characteristics, which are supposedly unique to IB, are present simultaneously in one illustrative $\mathrm{OB}$ domain. As one of many possible examples, consider the literature on inclusion and diversity. First, regarding multiplicity, groups are composed of individuals with different characteristics including demographic and functional backgrounds. Individuals themselves also hold a diversity of multiple identities (Ramarajan, 2014). Enhancing multiplicity further, there are also differences between objective and perceived indicators of diversity (Shemla et al., 2016). Moreover, group diversity is multilevel in nature, with individual identities, attitudes, and behaviors 
Table 1 Summary of similarities in three complexity dimensions across international business, organizational behavior, strategic management studies, and entrepreneurship

\begin{tabular}{|c|c|c|c|c|}
\hline \multirow{2}{*}{$\begin{array}{l}\text { Complexity } \\
\text { dimension }\end{array}$} & \multicolumn{4}{|c|}{ Field } \\
\hline & International business & Organizational behavior & $\begin{array}{l}\text { Strategic management } \\
\text { studies }\end{array}$ & Entrepreneurship \\
\hline Multiplicity & $\begin{array}{l}\text { Large number and variety } \\
\text { of actors, industries, } \\
\text { countries, contexts, } \\
\text { cultures, or institutions in } \\
\text { the global economic } \\
\text { system }\end{array}$ & $\begin{array}{l}\text { Large number and variety of } \\
\text { actors, contexts, cultures, } \\
\text { and levels of analyses (e.g., } \\
\text { gender, social class, income, } \\
\text { and occupation in } \\
\text { organizational demography } \\
\text { research) }\end{array}$ & $\begin{array}{l}\text { Large number and variety of } \\
\text { factors explaining firm } \\
\text { heterogeneity (e.g., variety } \\
\text { of indicators and sources of } \\
\text { variation in firm } \\
\text { performance) }\end{array}$ & $\begin{array}{l}\text { Large number and variety of } \\
\text { opportunities in complex } \\
\text { environments consisting of } \\
\text { different contexts and actors } \\
\text { (e.g., start-ups search for } \\
\text { and build relationships with } \\
\text { those who can supply } \\
\text { resources) }\end{array}$ \\
\hline Multiplexity & $\begin{array}{l}\text { Large number and variety } \\
\text { of relationships and } \\
\text { interdependencies among } \\
\text { entities }\end{array}$ & $\begin{array}{l}\text { Large number and variety of } \\
\text { relationships and } \\
\text { interdependencies among } \\
\text { people and groups (e.g., } \\
\text { group members becoming } \\
\text { "infected" by others' } \\
\text { emotional states in } \\
\text { emotional contagion } \\
\text { research) }\end{array}$ & $\begin{array}{l}\text { Large number and variety of } \\
\text { interlocking relationships } \\
\text { between organizational } \\
\text { capabilities, competitive } \\
\text { groups, networks, and } \\
\text { business ecosystems (e.g., } \\
\text { interdependencies among } \\
\text { different levels of corporate } \\
\text { diversification strategies) }\end{array}$ & $\begin{array}{l}\text { Large number and variety of } \\
\text { network relationships and } \\
\text { interdependencies that } \\
\text { affect the entrepreneurial } \\
\text { process (e.g., start-ups } \\
\text { forming multiplex and } \\
\text { multifaceted ties with } \\
\text { partners) }\end{array}$ \\
\hline Dynamism & $\begin{array}{l}\text { Constant change, activity, } \\
\text { or progress in } \\
\text { environments, } \\
\text { relationships, and } \\
\text { constructs }\end{array}$ & $\begin{array}{l}\text { Constant change, activity, } \\
\text { or progress in individual and } \\
\text { group attitudes and } \\
\text { behaviors (e.g., variation in } \\
\text { job performance over short } \\
\text { and long time frames) }\end{array}$ & $\begin{array}{l}\text { Constant change in firm } \\
\text { adaptation to volatile } \\
\text { environments (e.g., } \\
\text { balancing needs for } \\
\text { exploration and exploitation } \\
\text { to attain long-term viability } \\
\text { in the face of a changing } \\
\text { environment) }\end{array}$ & $\begin{array}{l}\text { Constant change, risk, and } \\
\text { instability inherent in new } \\
\text { value creation (e.g., } \\
\text { environmental conditions } \\
\text { that facilitate the creation } \\
\text { and destruction of business } \\
\text { in entrepreneurial } \\
\text { dynamism research) }\end{array}$ \\
\hline
\end{tabular}

embedded within group processes and outcomes (Joshi \& Neely, 2018). Second, regarding multiplexity, inclusion and diversity research grapples with a large number and variety of relationships and interdependencies among identities and people. For example, Joshi and Neely (2018) considered team diversity to be a team-level construct that represents differences among members of an interdependent workgroup with respect to specific social or cultural attributes. Moreover, they consider team diversity a structurally constrained phenomenon because its manifestation in teams is determined by the nature of the occupational, industry, and organizational context in which these teams are inherently embedded. The structural context refers to power and status differences between social groups inherent in the broader societal structure, and these facets of the context shape the salience, meaning, and content of diversity in teams (Johns, 2018). Third, regarding dynamism, the meaning of and types of diversity evolve over time. For example, Nkomo and Hoobler (2014) examined diversity ideologies and provided insights into how changes in societal beliefs and attitudes about non-dominant racioethnic groups and their status and incorporation into society have influenced the trajectory of diversity practice and research.

Finally, similar to IB, OB is also interdisciplinary. Specifically, organizational behavior draws on a variety of disciplines for its theories and methods, such as social psychology, behavioral economics, sociology, and neuroscience (Mitchell, 2018; Porter \& Schneider, 2014). OB has been heavily influenced by industrial and organizational psychology, which has an individual differences focus. The behavioral aspects of social psychology, sociology, and economics also facilitated the development of OB, combined with the push to include a strong behavioral emphasis in schools of business administration (Porter \& Schneider, 2014). As an example of the interdisciplinary nature of $\mathrm{OB}$ theories, cognitive and social psychological theories on motivation, decision-making, and self-efficacy are foundational to expectancy theory (Vroom, 1964) 
and goal setting theory (Locke \& Latham, 2020), which are two of the most prominent theories of work motivation in OB.

\section{Strategic Management Studies (SMS)}

In SMS, the goal is to understand business concepts that affect firm performance such as firms' internal strengths and weakness relative to their opportunities and threats (Hoskisson et al., 1999). Each of the three dimensions of complexity plays a critical role. Regarding multiplicity, SMS researchers have sought to explain firm heterogeneity for decades, and these efforts have required theoretical and methodological pluralism given that differences among firms depend on many factors (Durand et al., 2017). For example, consider research on indicators of and sources of variation in performance. This research stream adopts a multilevel perspective to examine the relative importance of business unit, corporation, industry, and year effects on business unit performance (e.g., Guo, 2017). Regarding multiplexity, an issue of key theoretical importance is the variety of interlocking relationships between organizational capabilities, competitive groups, networks, and business ecosystems. For example, consider research on the interdependencies between different levels of corporate diversification strategies, and how firms can successfully deploy and develop their strategic human assets while managing the trade-offs in their service and geographical diversification strategies (Kor \& Leblebici, 2005). Finally, regarding dynamism, SMS is concerned with how firms adapt to volatile environments and how they, for example, balance needs for exploration and exploitation to attain long-term viability in the face of a changing environment (e.g., March, 1991). For example, researchers have explored different dimensions of environmental dynamism (e.g., frequency and amplitude; Kim \& Rhee, 2009) and their effects on the evolution of organizational knowledge.

As we illustrated earlier regarding $\mathrm{OB}$, in SMS there are also many domains in which the three dimensions of complexity co-exist. As one of several possible illustrations, consider stakeholder theory (Verbeke \& Tung, 2013), which emerged as a way to explain the complexities of creating and trading value, connections between ethics and capitalism, and manager mindsets about influence of groups besides shareholders (Parmar et al., 2010). Stakeholder theory conceptualizes a business as a set of relationships among groups that have a stake in the business activities (Freeman, 2010).
Therefore, research needs to account for the ways groups made up of a variety of people with different interests sustainably work together and change the firm over time. So, regarding multiplicity, many stakeholders are involved in and contribute to firm performance. Further, these stakeholders have heterogeneous motives (Bridoux \& Stoelhorst, 2014). Regarding multiplexity, organizations and stakeholders are interdependent, meaning organizational survival and success are jointly determined (Bundy et al., 2018). As one example, Bundy et al. (2018) described organization-stakeholder fit as a way to explain cooperative behavior between an organization and its stakeholders. It describes the compatibility that exists between an organization and a stakeholder when their characteristics are well matched. Finally, regarding dynamism, environments where stakeholders and organizations interact change over time. Relationships among stakeholders and organizations are also dynamic. For example, Harrison et al. (2010) argued that trust between stakeholders and organizations develops dynamically.

Finally, SMS is also interdisciplinary. As Schendel (1994: 2) noted, "Strategic management is fundamentally an interdisciplinary subject, a field of practice and application, whose perspectives will shift and whose research approaches will be incommensurable, rendering it unlikely that a single paradigm will ever govern the field." SMS theories rely on and overlap with economics, sociology, marketing, political science, finance, public policy, and psychology (Leiblein \& Reuer, 2020; Nag et al., 2007). As one example of the way SMS theories draw on other disciplines, transaction cost economics, which is one of the most influential SMS theories, relies on psychology and behavioral economics to explain the behavioral processes that frame the governance of transactions (e.g., bounded rationality, opportunism; Cuypers et al., 2021).

\section{Entrepreneurship}

The goal of the field of entrepreneurship is to understand the process of the entrepreneurial act and its success or failure within certain environmental conditions (Bruyat \& Julien, 2001). Similar to OB and SMS, each of the three dimensions of complexity also plays a critical role. Regarding multiplicity, central to entrepreneurship research is understanding how entrepreneurs seek a variety of opportunities (Davidsson, 2015) in vast, complex environments consisting of different contexts and 
actors. For example, start-ups have a high need for resources and must search for and build relationships with those who can supply resources (Knoben $\&$ Bakker, 2019). As an example of the multilevel nature of entrepreneurship, context has an impact on new venture creation. Specifically, contextual influences at different levels complement personal agency in driving or inhibiting the translation of entrepreneurial intention into new venture creation (Meoli et al., 2020). Regarding multiplexity, entrepreneurship research seeks to understand how networks affect the entrepreneurial process and lead to positive outcomes for entrepreneurs and their firms, as well as how entrepreneurial processes and outcomes in turn influence network development (Hoang \& Antoncic, 2003). For example, Knoben and Bakker (2019) found that start-ups that engage in relational pluralism, forming multiplex and multifaceted ties with partners, perform better than both start-ups that form no alliances and startups that form stand-alone alliances. Finally, regarding dynamism, entrepreneurship is concerned with capturing at multiple levels the risk and instability inherent in engaging in new value creation. For example, at the environmental level, research in entrepreneurial dynamism has explored conditions that facilitate the creation and destruction of business (Bennett, 2019).

The literature on entrepreneurial orientation (EO) is an excellent illustration of the simultaneous presence of all three complexity dimensions. EO refers to the processes, practices, and decisions that lead to new entry (Lumpkin \& Dess, 1996). In terms of multiplicity, entrepreneurship scholars have determined that EO is a behavioral construct defined by firm actions. Putting aside the ongoing debate about EO being potentially tautological, this construct includes a variety of distinct but related behaviors, and researchers have sought to understand what specifically these behaviors are, who is likely to display them, and how they are enacted (Covin \& Wales, 2012). Regarding multiplexity, entrepreneurship researchers have explored the role of networks and the firm's ability to develop and utilize inter-organizational relationships and the resulting resources. In other words, EO is linked to firm performance at least in part because networks facilitate resource acquisition (Jiang et al., 2018) and strengthen the benefits of EO (Walter et al., 2006). Finally, in terms of dynamism, firms that exhibit EO place themselves in contexts characterized by uncertainty (Covin \& Wales, 2019). EO also has a temporal dimension, meaning that firms must exhibit entrepreneurial behaviors on an ongoing and sustained basis such that the pattern of behavior is generally recognized as a defining attribute of the firm (Covin \& Lumpkin, 2011). Therefore, research on EO must rely on data collected over time rather than a discrete act of entrepreneurship.

Finally, entrepreneurship is also interdisciplinary. Entrepreneurship theories draw on psychology, economics, sociology, political science, anthropology, and sustainability, to name a few (McMullen, 2019; Shepherd, 2015). As one example of the interdisciplinary nature of entrepreneurship, a large body of research explores entrepreneurial cognition, including entrepreneurs' individual attributes and cognitive processes that lead them to identify opportunities. This domain relies on cognitive psychological theory about how individuals notice, interpret, and evaluate potential opportunities (Shepherd, 2015). Therefore, as McMullen (2019: 414) noted, "It is difficult to imagine a field of entrepreneurship that can be understood as anything but interdisciplinary."

Given the similar centrality of multiplicity, multiplexity, and dynamism in OB, SMS, and entrepreneurship, as well as their common interdisciplinary nature, why is IB considered so unique regarding these dimensions? Next, we offer the perspective that social psychological research provides as a possible explanation.

\section{EXPLAINING THE UNIQUENESS PERSPECTIVE: FALSE UNIQUENESS BIAS}

There is a rather large conceptual and empirical social psychology literature regarding cognitive biases that we use to explain the uniqueness perspective. Cognitive biases are information-processing rules (i.e., mental shortcuts) also referred to as "heuristics." Specifically, false uniqueness bias is the tendency for people to underestimate the proportion of others who share their attributes (Galesic et al., 2018; Goethals et al., 1991; Suls, 2007; Suls \& Wan, 1987). This bias results in the belief that our characteristics are more uncommon and rare than they actually are (Perloff \& Brickman, 1982). Social and cognitive psychologists have explored explanations for these biased judgments in the form of interconnected underlying mechanisms including selective accessibility and focalism (Chambers, 2008). We emphasize that we are most certainly not accusing IB scholars of being affected by this heuristic as a "personal psychological 
defect." Similarly, we are not accusing the IB profession as a whole of this bias.

First, selective accessibility occurs when we are primed with some sort of information and, when subsequently making a comparison, we are more likely to retrieve knowledge from memory that is consistent with the primed information (Mussweiler et al., 2017; Mussweiler \& Strack, 1999). For example, if we read an article or attend a conference session highlighting the methodological challenges supposedly unique to IB, when subsequently making a comparison between IB and other fields, we will have an easier time recalling information consistent with the argument that IB is different from other fields. Further, using the classic availability heuristic (Tversky \& Kahneman, 1974), the information we readily recall about ourselves will be used when making judgments in relation to others. In other words, when considering whether our field is uniquely complex, what readily comes to mind are examples we ourselves have experienced from our research, teaching, or have read in journals in our field.

Second, focalism is the tendency to give disproportionate weight to information that has our immediate attention (Wilson et al., 2000). This concept is especially relevant in the case of academic research where we are surrounded with information in our own field through conducting research, teaching, reading the literature, and communicating with colleagues. Because this information is at the forefront of our attention, we give disproportionate weight to it relative to equally relevant information in the background.

Clearly, false uniqueness bias may not be the sole explanation for the IB uniqueness perspective. However, we offer it as plausible one and look forward to future research addressing additional explanations.

\section{ADVANTAGES AND OPPORTUNITIES FROM NOT BEING UNIQUE}

Our perspective is that although it may have been advantageous for IB to claim uniqueness in its early development stages, claiming uniqueness is no longer needed given that IB is now a mature and legitimate field (Cantwell \& Brannen, 2016). Our perspective is that we should no longer be concerned that IB as a field is at risk of "running out of steam" (Buckley, 2002). We believe that if IB continues to exaggerate its distinctly unique nature, given its supposed unique complexity, there is a risk of self-imposed isolation and lack of crosspollination with other fields.

To illustrate the rewards of capitalizing on synergies based on similarities between IB and other domains like OB, SMS, and entrepreneurship, we turn to JIBS Decade Award winners as exemplars of some of the most admired and impactful research produced by the field (Decade Award, 2021). To be considered for the award, an article must have been one of the five most highly cited articles published in the volume 10 years earlier. After reading and discussing the nominees, the committee selects the most influential article. Thus, citation counts establish the short list of articles considered for the award, but the final selection of the most influential article is determined by an informed debate among the selection committee members about the overall research impact of the five articles (Eden, 2009).

We examined each of the award recipients and found that there is a clear dominance of articles that focused on similarities between IB and other fields rather than the distinct uniqueness and complexity of IB (Decade Award, 2021). To illustrate the benefits of engaging in this type of scholarship, we comment on three that are particularly useful to illustrate that multiplicity, multiplexity, and dynamism are not only critical for IB but also for OB, SMS, and entrepreneurship. Accordingly, demonstrating commonalities rather than differences, these three articles include clear bridges between IB and each of these adjacent fields.

First, the 2014 JIBS Decade Award winner "Innovation, organizational capabilities, and the bornglobal firm" by Knight and Cavusgil (2004) provides an example of the new insights gained by identifying commonalities between IB and entrepreneurship. The authors explored born-global firms, which they considered a unique breed of international, entrepreneurial firms with an innovative culture; they leveraged the literature on entrepreneurial orientation to explain behaviorally how these firms develop and perform. IB and entrepreneurship are both interested in understanding new entry, especially in turbulent environments. Therefore, this article addressed the three dimensions of complexity facing both IB and entrepreneurship researchers. In terms of multiplicity, Knight and Cavusgil (2004) explored the various resources young firms may develop and deploy in diverse international markets. They found that because these young firms do not have 
tangible resources, they rely on intangible knowledge-based resources. They also addressed context and level of analysis in that most research at the time identified trends of globalization and technology as facilitating early internationalization. Instead, they looked deeper at the processes and capabilities of these entrepreneurial firms. In terms of multiplexity, there is a large number and variety of relationships and interdependencies among resources and capabilities in the knowledge-building and routinization processes. Knight and Cavusgil (2004) found that born-global firms leverage a unique mix of orientations and strategies that help them succeed in diverse international markets. In terms of dynamism, born-global firms provide a perfect example of how innovation plays out in turbulent environments, which is a phenomenon common to both IB and entrepreneurship. The concept of a born-global firm is also inherently related to dynamism in time. These firms are young and operate internationally from an early stage in their development.

As a second exemplar, the 2019 JIBS Decade Award winner "The Uppsala internationalization process model revisited: From liability of foreignness to liability of outsidership" by Johanson and Vahlne (2009) relied on similar complexities in IB and SMS to develop a business network model of the internationalization process. Johanson and Vahlne (2009) revisited their Uppsala internationalization process model in light of theoretical advances over the past decades. The main improvements in their new model resulted from bridging IB and business network research, which has been used predominantly in SMS. They viewed markets as networks of relationships where firms are linked to each other in varied and complex patterns. The implications are that insidership in relevant networks is necessary for successful internationalization, and that relationships offer potential for learning and for building trust and commitment. Their resulting framework more fully captures the three dimensions of complexity in both IB and SMS. In terms of multiplicity, there is a large number and variety of actors, industries, countries, contexts, and institutions in market networks. There are also countless opportunities in the environment, and they theorized that opportunities emerge as network partners develop knowledge. These countless opportunities also refer to the wide variety of entry mode and location choices in internationalization processes. In terms of multiplexity, central to their internationalization process model is the large number and variety of relationships and interdependencies among firms. Johanson and Vahlne (2009: 1423) viewed the firm as "embedded in an enabling, and at the same time constraining, business network that includes actors engaged in a wide variety of interdependent relationships." By leveraging business network research in SMS and integrating it with internationalization research in IB, the authors were able to view the firm and its environment differently than the previous neoclassical market view with many independent suppliers and customers. In terms of dynamism, central to their model is uncertainty and time. In their revised model, outsidership in a relevant network is at the root of uncertainty. Creating trust and knowledge in working relationships also takes significant time. By viewing internationalization from a network perspective, they consider how relationships and learning develop, which ultimately led them to add trust-building and knowledge-creation as change mechanisms.

Third, the 2020 JIBS Decade Award winner "Unraveling the effects of cultural diversity in teams: A meta-analysis of research on multicultural work groups" by Stahl et al. (2010) provides an excellent example of similarities between OB and IB, two fields that seemed to have produced inconsistent and often contradictory findings on the impact of team diversity on performance. In improving our understanding of the mechanisms and contextual conditions under which cultural diversity affects team processes, Stahl et al. (2010) directly addressed all three dimensions of complexity that similarly challenge $\mathrm{OB}$ and $\mathrm{IB}$ team diversity researchers. In terms of multiplicity, Stahl et al. (2010: 693) explained that although IB research has typically considered country a proxy for culture, "because culture is a complex construct, with multiple effects," there is a need to examine different dimensions of cultural diversity (e.g., surface-level versus deep-level; intranational versus cross-national). They used psychology theories from $\mathrm{OB}$ to explain the mechanisms through which different types of diversity impact group dynamics, and they detailed various contextual conditions under which cultural diversity affects team processes. In terms of multiplexity, the authors' topic of teams highlights the complexity that comes from examining how groups composed of individuals with varied characteristics interact and engage in interdependent tasks. Further, three (i.e., task complexity, team size, and team dispersion) out of four moderators studied capture the large number 
and variety of relationships and interdependencies in teams. In terms of dynamism, their framework and meta-analysis illuminate how relationships, team dynamics, and contexts change. The moderator team tenure captures how team processes change the longer a team has worked together and reflects the potential that team processes result in gains and losses that accumulate over time. For future directions, the authors called for research using more dynamic process-oriented moderator variables, such as boundary-spanning activities. This article was also particularly exemplary for its time in the use of meta-analysis, a method used not only in IB but also extensively in $\mathrm{OB}$ and other fields (Steel et al., 2021). Meta-analysis allowed for detecting moderating effects not testable in the primary studies, which is especially important for reconciling past results relying on different operationalizations of variables and study designs. Because their meta-analysis analyzed intermediate outcomes, moderators, and study design characteristics, it found complementary explanations for the lack of a direct relationship between cultural diversity and team performance. Overall, the 2020 JIBS Decade Award winner demonstrated similarities between IB and OB and, therefore, not only enhanced our understanding of a vast literature with conflicting findings, but also used the commonalities between IB and OB to gain new important insights and open doors for theory building.

As we described, a common denominator across the aforementioned three exemplars and other JIBS Decade Award winners is their permeability regarding their theoretical orientation. In most cases, they adopted a dual domestic-borrowed theory orientation which combines theories considered "indigenous" to IB with others imported from other fields (e.g., OB, economics, psychology, sociology). A similar phenomenon has occurred in SMS. For example, Kenworthy and Verbeke (2015) ascertained that five of the top 10 most frequently used theories are indigenous in that they originated within management or include substantial SMS contributions (i.e., transaction cost economics in the realm of studying diversification, selecting governance modes, and transferring knowledge; the resource based view; upper echelon theory; contingency theory; and stakeholder theory). However, three of the top ten most frequently used theories in SMS have been borrowed from sociology (i.e., institutional theory, resource dependence theory, and social capital theory), and two from economics (i.e., agency theory and signaling theory).

Has the progress of SMS been delayed due to an overreliance on borrowed theories? Should IB discontinue the use of borrowed theories and, instead, focus mainly on developing and testing indigenous theories? Will IB's progress accelerate as a consequence of developing indigenous theories compared to borrowing theories from other fields? We believe that these questions are based on the assumption of IB's (and SMS') uniqueness. Instead, the JIBS Decade Award winners demonstrate that the "domestic versus imported" dichotomization may not be productive in terms of IB's theoretical advancement. Rather than automatically excluding a theory originating in another field due to a fear that overreliance on foreign theories may delay IB's progress, theoretical permeability involves a careful and critical selection process. Specifically, Kenworthy and Verbeke (2015, Table 4) offered seven criteria to assess the appropriateness of importing a theory into SMS, and these criteria are just as useful for selecting theories to be imported into IB: (i) predictive power (e.g., does the borrowed theory consistently demonstrate statistically significant, predictive power in its base discipline?), (ii) explanatory power (i.e., does the borrowed theory possess substantial explanatory power in its base discipline?), (iii) absence of strong competing theories (i.e., are there strong rival theories providing alternative explanations in the base discipline?), (iv) issues match (e.g., are the key phenomena and problems studied reasonably similar in the borrowed theory discipline and the borrower discipline?), (v) consistency in concepts (i.e., are the key concepts used in the borrowed theory consistent with and meaningful in the borrower discipline?), (vi) consistency in assumptions (i.e., are the key underlying assumptions in the borrowed theory consistent with the underlying assumptions in the borrower discipline?), and (vii) knowledge fit (e.g., is there extant evidence in the borrower discipline to support or refute the key propositions of the borrowed theory?). So, the process of borrowing theories from other fields is a far cry from a mindless importation process. But, the starting point requires a focus on similarities between IB and other fields rather than IB's supposed uniqueness. Then, the next step involves the critical use of selectivity criteria so that imported theories are appropriate and useful (Kenworthy \& Verbeke, 2015). 


\section{CONCLUSION}

Is the field of international business studies unique based on the three complexity dimensions of multiplicity, multiplexity, and dynamism, and its interdisciplinary nature? We provided the alternative perspective that IB is not so uniquely complex compared to the adjacent fields of organizational behavior, strategic management, and entrepreneurship. Clearly, there have been advantages associated with claiming uniqueness when IB was in its nascent stage. But, our perspective is that IB is now a mature, established, and legitimate field, and therefore it has more to gain by highlighting theoretical and methodological similarities rather

\section{REFERENCES}

About the IM Division. 2021. The international management division of the academy of management. https://im.aom.org/. Accessed 12 July 2021.

Aguinis, H. 2019. Performance management (4th ed). Chicago Business Press.

Aguinis, H., Gottfredson, R. K., \& Culpepper, S. A. 2013. Bestpractice recommendations for estimating cross-level interaction effects using multilevel modeling. Journal of Management, 39(6): 1490-1528.

Aguinis, H., Ramani, R. S., \& Cascio, W. F. 2020. Methodological practices in international business research: An after-action review of challenges and solutions. Journal of International Business Studies, 51(9): 1593-1608.

Andersson, U., Cuervo-Cazurra, A., \& Nielsen, B. B. 2020. Explaining interaction effects within and across levels of analysis. In L. Eden, B. Nielsen, \& A. Verbeke (Eds.), Research methods in international business: 331-349. Palgrave Macmillan.

Arregle, J. L., Hébert, L., \& Beamish, P. W. 2006. Mode of international entry: The advantages of multilevel methods. Management International Review, 46(5): 597-618.

Ashkanasy, N. M., \& Dorris, A. D. 2017. Emotions in the workplace. Annual Review of Organizational Psychology and Organizational Behavior, 4: 67-90.

Bello, D. C., \& Kostova, T. 2012. From the editors: Conducting high impact international business research: The role of theory. Journal of International Business Studies, 43(6): 537-543.

Bennett, D. L. 2019. Infrastructure investments and entrepreneurial dynamism in the US. Journal of Business Venturing, 34(5): 105907.

Birkinshaw, J., Brannen, M. Y., \& Tung, R. L. 2011. From a distance and generalizable to up close and grounded: Reclaiming a place for qualitative methods in international business research. Journal of International Business Studies, 42(5): 573-581.

Bridoux, F., \& Stoelhorst, J. W. 2014. Microfoundations for stakeholder theory: Managing stakeholders with heterogeneous motives. Strategic Management Journal, 35(1): 107-125.

Bruyat, C., \& Julien, P. A. 2001. Defining the field of research in entrepreneurship. Journal of Business Venturing, 16(2): $165-180$.

Buckley, P. J. 2002. Is the international business research agenda running out of steam? Journal of International Business Studies, 33(2): 365-373. than uniqueness-which may lead to self-imposed isolation. We see a bright future and impact for IB based on the fact that JIBS Decade Award winners have precisely focused on similarities rather than uniqueness, which has resulted in bridges with $\mathrm{OB}$, SMS, and entrepreneurship that are beneficial for all fields involved. Continuing to build bridges, rather than walls, will allow IB to selectively import and export theories and methods and thereby make IB borders even more permeable. In turn, these synergies are likely to result in further theoretical progress that will benefit IB research, IB practice, and enhance IB's positive impact on society even further.

Buckley, P. J., \& Casson, M. 2001. Strategic complexity in international business. In A. M. Rugman, \& T. L. Brewer (Eds.), Oxford handbook of international business: 88-126. Oxford University Press.

Buckley, P. J., Doh, J. P., \& Benischke, M. H. 2017. Towards a renaissance in international business research? Big questions, grand challenges, and the future of IB scholarship. Journal of International Business Studies, 48(9): 1045-1064.

Bundy, J., Vogel, R. M., \& Zachary, M. A. 2018. Organizationstakeholder fit: A dynamic theory of cooperation, compromise, and conflict between an organization and its stakeholders. Strategic Management Journal, 39(2): 476-501.

Cantwell, I.\& \& Brannen, M. Y. 2011. Positioning JIBS as an interdisciplinary journal. Journal of International Business Studies, 42(1): 1-9.

Cantwell, J., \& Brannen, M. Y. 2016. The changing nature of the international business field, and the progress of JIBS. Journal of International Business Studies, 47(9): 1023-1031.

Cantwell, J., Piepenbrink, A., \& Shukla, P. 2014. Assessing the impact of JIBS as an interdisciplinary journal: A network approach. Journal of International Business Studies, 45(7): 787-799.

Chambers, J. R. 2008. Explaining false uniqueness: Why we are both better and worse than others. Social and Personality Psychology Compass, 2(2): 878-894.

Cheng, J. L., Birkinshaw, J., Lessard, D. R., \& Thomas, D. C. 2014. Advancing interdisciplinary research: Insights from the JIBS special issue. Journal of International Business Studies, 45(6): 643-648.

Cheng, J. L., Henisz, W. J., Roth, K., \& Swaminathan, A. 2009. From the editors: Advancing interdisciplinary research in the field of international business: Prospects, issues and challenges. Journal of International Business Studies, 40(7): 1070-1074.

Covin, J. G., \& Lumpkin, G. T. 2011. Entrepreneurial orientation theory and research: Reflections on a needed construct. Entrepreneurship Theory and Practice, 35(5): 855-872.

Covin, J. G., \& Wales, W. J. 2012. The measurement of entrepreneurial orientation. Entrepreneurship Theory and Practice, 36(4): 677-702.

Covin, J. G., \& Wales, W. J. 2019. Crafting high-impact entrepreneurial orientation research: Some suggested guidelines. Entrepreneurship Theory and Practice, 43(1): 3-18.

Cuervo-Cazurra, A., Andersson, U., Brannen, M. Y., Nielsen, B. B., \& Reuber, A. R. 2016. From the editors: Can I trust your findings? Ruling out alternative explanations in international 
business research. Journal of International Business Studies, 47(8): 881-897.

Cuervo-Cazurra, A., Caligiuri, P., Andersson, U., \& Brannen, M. Y. 2013. From the editors: How to write articles that are relevant to practice. Journal of International Business Studies, 44(4): 285-289.

Cuypers, I. R., Ertug, G., Cantwell, J., Zaheer, A., \& Kilduff, M. 2020. Making connections: Social networks in international business. Journal of International Business Studies, 51(5): 714-736.

Cuypers, I. R., Hennart, J. F., Silverman, B. S., \& Ertug, G. 2021. Transaction cost theory: Past progress, current challenges, and suggestions for the future. Academy of Management Annals, 15(1): 111-150.

Dalal, R. S., Alaybek, B., \& Lievens, F. 2020. Within-person job performance variability over short timeframes: Theory, empirical research, and practice. Annual Review of Organizational Psychology and Organizational Behavior, 7: 421-449.

Davidsson, P. 2015. Entrepreneurial opportunities and the entrepreneurship nexus: A re-conceptualization. Journal of Business Venturing, 30(5): 674-695.

Decade award: About the Journal of International Business Studies Decade Award. 2021. https://www.palgrave.com/jp/ journal/41267/volumes-issues/decade-award. Accessed 12 July 2021.

Doz, Y. 2011. Qualitative research for international business. lournal of International Business Studies, 42(5): 582-590.

Dunning, J. H. 1989. The study of international business: A plea for a more interdisciplinary approach. Journal of International Business Studies, 20(3): 411-436.

Durand, R., Grant, R. M., \& Madsen, T. L. 2017. The expanding domain of strategic management research and the quest for integration. Strategic Management Journal, 38(1): 4-16.

Eden, L. 2008. Letter from the editor-in-chief. Journal of International Business Studies, 39(1): 1-7.

Eden, L. 2009. Perspectives on international business: Insights from the 1970-1985 JIBS Decade Award Winners. Journal of International Business Studies, 40(9): 1581-1590.

Eden, L., \& Nielsen, B. B. 2020. Research methods in international business: The challenge of complexity. Journal of International Business Studies, 51(9): 1609-1620.

Eden, L., Nielsen, B. B., \& Verbeke, A. (Eds.). 2020. Research methods in international business. JIBS Special Collections. Palgrave Macmillan.

Fainshmidt, S., Judge, W. Q., Aguilera, R. V., \& Smith, A. 2018. Varieties of institutional systems: A contextual taxonomy of understudied countries. Journal of World Business, 53(3): 307-322.

Freeman, R.E., 2010. Strategic management: A stakeholder approach. Cambridge University Press.

Galesic, M., Olsson, H., \& Rieskamp, J. 2018. A sampling model of social judgment. Psychological Review, 125(3): 363-390.

Gemmetto, V., Squartini, T., Picciolo, F., Ruzzenenti, F., \& Garlaschelli, D. 2016. Multiplicity and multireciprocity in indirected multiplexes. Physical Review, 94(042316): 1-20.

Goerzen, A., Asmussen, C. G., \& Nielsen, B. B. 2013. Global cities and multinational enterprise location strategy. Journal of International Business Studies, 44(5): 427-450.

Goethals, G. R., Messick, D. M., \& Allison, S. T. 1991. The uniqueness bias: Studies of constructive social comparison. In J. Suls, \& T. A. Wills (Eds.), Social comparison: Contemporary theory and research, 149-176Lawrence Erlbaum Associates Inc. Guo, G. 2017. Demystifying variance in performance: A longitudinal multilevel perspective. Strategic Management Journal, 38(6): 1327-1342.

Harrison, J. S., Bosse, D. A., \& Phillips, R. A. 2010. Managing for stakeholders, stakeholder utility functions, and competitive advantage. Strategic Management Journal, 31(1): 58-74.

Hoang, H., \& Antoncic, B. 2003. Network-based research in entrepreneurship: A critical review. Journal of Business Venturing, 18(2): 165-187.
Hoskisson, R. E., Hitt, M. A., Wan, W. P., \& Yiu, D. 1999. Theory and research in strategic management: Swings of a pendulum. Journal of Management, 25(3): 417-456.

Jiang, X., Liu, H., Fey, C., \& Jiang, F. 2018. Entrepreneurial orientation, network resource acquisition, and firm performance: A network approach. Journal of Business Research, 87(C): 46-57.

Johanson, J., \& Vahlne, J. E. 2009. The Uppsala internationalization process model revisited: From liability of foreignness to liability of outsidership. Journal of International Business Studies, 40(9): 1411-1431.

Johns, G. 2018. Advances in the treatment of context in organizational research. Annual Review of Organizational Psychology and Organizational Behavior, 5: 21-46.

Jones, G., \& Khanna, T. 2006. Bringing history (back) into international business. Journal of International Business Studies, 37(4): 453-468.

Joshi, A., \& Neely, B. H. 2018. A structural-emergence model of diversity in teams. Annual Review of Organizational Psychology and Organizational Behavior, 5: 361-385.

Kenworthy, T. P., \& Verbeke, A. 2015. The future of strategic management research: Assessing the quality of theory borrowing. European Management Journal, 33(3): 179-190.

Kim, T., \& Rhee, M. 2009. Exploration and exploitation: Internal variety and environmental dynamism. Strategic Organization, 7(1): 11-41.

Klein, K. J., \& Kozlowski, S. W. (Eds.). 2000. Multilevel theory, research, and methods in organizations: Foundations, extensions, and new directions. Jossey-Bass.

Knight, G. A., \& Cavusgil, S. T. 2004. Innovation, organizational capabilities, and the born-global firm. Journal of International Business Studies, 35(2): 124-141.

Knoben, J., \& Bakker, R. M. 2019. The guppy and the whale: Relational pluralism and start-ups' expropriation dilemma in partnership formation. Journal of Business Venturing, 34(1): 103-121.

Kor, Y. Y., \& Leblebici, H. 2005. How do interdependencies among human-capital deployment, development, and diversification strategies affect firms' financial performance? Strategic Management Journal, 26(10): 967-985.

Leiblein, M., \& Reuer, J. 2020. Foundations and futures of strategic management. Strategic Management Review, 1(1): $1-33$.

Li, J., Ding, H., Hu, Y., \& Wan, G. 2021. Dealing with dynamic endogeneity in international business research. Journal of International Business Studies, 52(3): 339-362.

Locke, E. A., \& Latham, G. P. 2020. Building a theory by induction: The example of goal setting theory. Organizational Psychology Review, 10(3-4): 223-239.

Lumpkin, G. T., \& Dess, G. G. 1996. Clarifying the entrepreneurial orientation construct and linking it to performance. Academy of Management Review, 21(1): 135-172.

Luthans, F., Luthans, B. C., \& Luthans, K. W. 2015. Organizational behavior: An evidence-based approach (13th ed.). North Carolina: IAP-Information Age Publishing.

March, J. G. 1991. Exploration and exploitation in organizational learning. Organization Science, 2(1): 71-87.

McMullen, J. S. 2019. A wakeup call for the field of entrepreneurship and its evaluators. Journal of Business Venturing, 34(3): 413-417.

Meoli, A., Fini, R., Sobrero, M., \& Wiklund, J. 2020. How entrepreneurial intentions influence entrepreneurial career choices: The moderating influence of social context. Journal of Business Venturing, 35(3): 105982.

Mitchell, T. R. 2018. A dynamic, inclusive, and affective evolutionary view of organizational behavior. Annual Review of Organizational Psychology and Organizational Behavior, 5: $1-19$.

Mussweiler, T., Michels, C., \& Weiss, A. 2017. Reflections on comparison: The selective accessibility mechanism. In R. Deutsch, B. Gawronski, \& W. Hofmann (Eds.), Reflective and 
impulsive determinants of human behavior: 19-33. Milton Park: Routledge/Taylor \& Francis Group.

Mussweiler, T., \& Strack, F. 1999. Comparing is believing: A selective accessibility model of judgmental anchoring. In W. Stroebe, \& M. Hewstone (Eds.), European review of social psychology: 135-168, vol. 10. Chichester, UK: Wiley.

Nag, R., Hambrick, D. C., \& Chen, M. J. 2007. What is strategic management, really? Inductive derivation of a consensus definition of the field. Strategic Management Journal, 28(9): 935-955.

Nkomo, S., \& Hoobler, J. M. 2014. A historical perspective on diversity ideologies in the United States: Reflections on human resource management research and practice. Human Resource Management Review, 24(3): 245-257.

Norder, K., Sullivan, D., Emich, K., \& Sawhney, A. 2021. Reanchoring the ontology of IB: A reply to Poulis \& Poulis. Academy of Management Perspectives, 35(2): 314-323.

Parmar, B. L., Freeman, R. E., Harrison, J. S., Wicks, A. C., Purnell, L., \& De Colle, S. 2010. Stakeholder theory: The state of the art. Academy of Management Annals, 4(1): 403-445.

Perloff, L. S., \& Brickman, P. 1982. False consensus and false uniqueness: Biases in perceptions of similarity. Academic Psychology Bulletin, 4(3): 475-494.

Peterson, M. F., Arregle, J. L., \& Martin, X. 2012. Multilevel models in international business research. Journal of International Business Studies, 43(5): 451-457.

Peterson, R. B. 2004. Empirical research in international management: A critique and future agenda. In R. MarschanPiekkari, \& C. Welch (Eds.), Handbook of qualitative research methods for international business: 25-55. Edward Elgar.

Porter, L. W., \& Schneider, B. 2014. What was, what is, and what may be in OP/OB. Annual Review of Organizational Psychology and Organizational Behavior, 1(1): 1-21.

Ramarajan, L. 2014. Past, present and future research on multiple identities: Toward an intrapersonal network approach. Academy of Management Annals, 8(1): 589-659.

Schendel, D. 1994. Introduction to the summer 1994 special issue -'Strategy: Search for New Paradigms'. Strategic Management Journal, 15(Summer 1994): 1-4.

Shemla, M., Meyer, B., Greer, L., \& Jehn, K. A. 2016. A review of perceived diversity in teams: Does how members perceive their team's composition affect team processes and outcomes? Journal of Organizational Behavior, 37(S1): S89-S106.

Shenkar, O. 2004. One more time: International business in a global economy. Journal of International Business Studies, 35(2): 161-171.

Shepherd, D. 2015. Party On! A call for entrepreneurship research that is more interactive, activity based, cognitively hot, compassionate, and prosocial. Journal of Business Venturing, 30(4): 489-507.

Stahl, G. K., Maznevski, M. L., Voigt, A., \& Jonsen, K. 2010. Unraveling the effects of cultural diversity in teams: A metaanalysis of research on multicultural work groups. Journal of International Business Studies, 41(4): 690-709.

Steel, P., Beugelsdijk, S., \& Aguinis, H. 2021. The anatomy of an award-winning meta-analysis: Recommendations for authors, reviewers, and users of meta-analytic reviews. Journal of International Business Studies, 52(1): 23-44.

Sullivan, D. P., \& Daniels, J. D. 2008. Innovation in international business research: A call for multiple paradigms. Journal of International Business Studies, 39(6): 1081-1090.

Sullivan, D., Nerur, S. P., \& Balijepally, V. 2011. Source or storer? IB's performance in a knowledge network. Journal of International Business Studies, 42(3): 446-457.

Suls, J. 2007. False uniqueness bias. In R. F. Baumeister, \& K. D. Vohs (Eds.), Encyclopedia of social psychology: 344-345, vol. 1. Thousand Oaks, CA: SAGE Publications Inc.

Suls, J., \& Wan, C. K. 1987. In search of the false-uniqueness phenomenon: Fear and estimates of social consensus. Journal of Personality and Social Psychology, 52(1): 211-217.
Sun, P., Mellahi, K., \& Thun, E. 2010. The dynamic value of MNE political embeddedness: The case of the Chinese automobile industry. Journal of International Business Studies, 41(7): 1161-1182.

Szkudlarek, B., Osland, J. S., Nardon, L., \& Zander, L. 2020. Communication and culture in international business-Moving the field forward. Journal of World Business, 55(6): 101126.

Teagarden, M. B., Von Glinow, M. A., \& Mellahi, K. 2018. Contextualizing international business research: Enhancing rigor and relevance. Journal of World Business, 53(3): 303-306.

Teece, D. J. 2014. A dynamic capabilities-based entrepreneurial theory of the multinational enterprise. Journal of International Business Studies, 45(1): 8-37.

Tversky, A., \& Kahneman, D. 1974. Judgment under uncertainty: Heuristics and biases. Science, 185(4157): 1124-1131.

Verbeke, A., \& Tung, V. 2013. The future of stakeholder management theory: A temporal perspective. Journal of Business Ethics, 112(3): 529-543.

Vroom, V. H. 1964. Work and motivation. Wiley.

Walter, A., Auer, M., \& Ritter, T. 2006. The impact of network capabilities and entrepreneurial orientation on university spinoff performance. Journal of Business Venturing, 21(4): 541-567.

Wilson, T. D., Wheatley, T., Meyers, J. M., Gilbert, D. T., \& Axsom, D. 2000. Focalism: A source of durability bias in affective forecasting. Journal of Personality and Social Psychology, 78(5): 821-836.

Yeheskel, O., \& Shenkar, O. 2009. Knowledge flows in international business: A JIBS citation analysis. EuroMed Journal of Business, 4(2): 111-126.

\section{ABOUT THE AUTHORS}

Herman Aguinis is the Avram Tucker Distinguished Scholar and Department of Management Chair at The George Washington University School of Business. His research focuses on global talent management and research methods. He has published more than 180 articles in refereed journals and nine books and is serving as President of the Academy of Management during 2021-2022. The 2020, 2019, and 2018 Web of Science Highly Cited Researchers Reports ranked him among the world's 100 most impactful researchers in Economics and Business and he received awards for lifetime scientific contributions from the Academy of Management, Society for Industrial and Organizational Psychology, and Society for Human Resource Management.

Kelly P. Gabriel is a PhD student in Management at The George Washington University School of Business. Her research focuses on diversity, inclusion, and equity, social justice, and research methods. Her research has been published in Business \& Society, Business Horizons, and Management Research. She earned her Master of Science in Psychology and Bachelor's in Business Administration from Villanova University. 
Open Access This article is licensed under a Creative Commons Attribution 4.0 International License, which permits use, sharing, adaptation, distribution and reproduction in any medium or format, as long as you give appropriate credit to the original author(s) and the source, provide a link to the Creative Commons licence, and indicate if changes were made. The images or other third party material in this article are included in the article's
Creative Commons licence, unless indicated otherwise in a credit line to the material. If material is not included in the article's Creative Commons licence and your intended use is not permitted by statutory regulation or exceeds the permitted use, you will need to obtain permission directly from the copyright holder. To view a copy of this licence, visit http://creativecommons.org/licenses/by/4.0/.

Publisher's Note Springer Nature remains neutral with regard to jurisdictional claims in published maps and institutional affiliations.

Accepted by Alain Verbeke, Editor-in-Chief, 12 July 2021. This article has been with the authors for one revision. 